\title{
The Development of Japanese Modality and the Influence of Bilingual Acquisition
}

\author{
Masumi Kai \\ College of Liberal Arts \& Social Sciences, University of Guam, United States
}

Copyright $(2016$ by authors, all rights reserved. Authors agree that this article remains permanently open access under the terms of the Creative Commons Attribution License 4.0 International License

\begin{abstract}
This paper examines the development of Japanese modality in children's speech and the influence of bilingual acquisition. We use data collected longitudinally from six Japanese monolingual children and three Japanese-English bilingual children. We compare their speech to analyze if there are any influences during the development of Japanese modality when acquiring two languages. Our data shows that children start using a variety of Japanese modal expressions before becoming five-years-old. Bilingual children also use a variety of modal expressions; however, the frequency rate of modal forms produced by an English dominant bilingual child is much lower than with a monolingual child. The results suggest that production frequency and the adequate usage of modal expressions may be used as an indicator in evaluating bilingual children's language development and performance.
\end{abstract}

Keywords Modality, Modal Expressions, Modal Forms, Sentence Final Particle, Acquisition Order, Bilingual

\section{Introduction}

Towards the middle of the nineteenth century, the Grammar-Translation Method was rejected due to a need for oral proficiency to communicate among Europeans. Language teaching specialists such as the Frenchmen C. Marcel (1793-1896) and F. Gouin (1931-1896), the Englishman T. Prendergast (1806-1886) turned their attentions to child language acquisition. Although their ideas and methods were not disseminated widely then, it opened up a path leading to the new research field of first language acquisition. The study of the Japanese language acquisition started out a little later. One of the first literature is the work by Kubo[24] on child's vocabulary learning in 1920s. Subsequently numerous discussions have been carried out. Scholars have been discussing different aspects of Japanese acquisition such as phonemes, vocabulary, word order, particles, verb conjugations, passive voice, noun modifying clauses, sentence final particles, and so on. Among the many aspects of a language, this paper focuses on modality acquisition. Modality reflects the speaker's mind. As Shatz and Wilcox[47] note, there is the influence of universal cognitive development on the acquisition of modality. Acquiring modality in part involves a process of socialization of cognition.

The discussion of Japanese modality can be found as early as the 1930s in Yamada[57] and subsequently in Mikami[36] in the late 1950s. There has been an enormous amount of research since then. Vigorous series of works on modality have been done by leading scholars such as S. Kinsui, T. Masuoka, K. Miyazaki, T. Moriyama, Y. Nitta, Y. Takubo, H. Teramura, and other many Japanese linguists. The research on the acquisition of modal expressions by adult Japanese language learners have also received vast attention in the past decades, and there are countless works analyzing learner's errors and the acquisition orders of modal expressions.

In contrast, the longitudinal research into Japanese modality development in children's language is limited. The research does exist mainly observe a limited number of children, usually one, and are not systematic investigations. The main reason is that it is very hard to keep the same participants for many years of data collection. Even keeping one participant for many years is quite difficult. Consequently, there are still many aspects of the Japanese L1 children's language acquisition that have not seen the limelight yet. Needless to say, bilingual development with Japanese as the first language also has not been discussed enough yet.

The purpose of this paper is firstly, to analyze multiple children's data and to investigate the developmental order of modal expressions, if any, as a starting point of discussion. Then, we will discuss if learning more than two languages has any impacts on modality development in bilinguals. We use spontaneous speech data collected longitudinally from six monolingual children and three bilingual children aged between $1 ; 1$ to $10 ; 1$. Bedore \& Peña[2] state that evaluating bilingual children's language abilities is made complex by the lack of standardized assessments. We believe that investigating children's modality acquisition will shed new light on how we evaluate bilingual children's language development and performance. 


\section{The Modal System in Japanese}

The traditional view divides modality into two main semantic types: 'epistemic modality' and 'deontic modality ${ }^{1}$. Epistemic modality expresses the speaker's judgements about possibility, degrees of certainty, or necessity of the truth in propositions. Deontic modality deals with the necessity or possibility of acts performed by morally responsible agents, and it thus associated with obligation, permission, and ability. Unfortunately, this binary categorization does not depict Japanese modality well. Modality is expressed in language in a variety of ways. Japanese modality is realized in the inflection of a predicate, sentence adverbs, interjection or interjectory particles, and intonation ([18]). The study of modality has gained much attention from many Japanese linguists since Yamada[57] and Mikami[36]. One of the unique characteristics of Japanese is that a Japanese sentence seldom ends with a bare proposition. Kokuritsu kokugo kenkyusho[23], Maynard[35], Mizutani[37], and other scholars claim that a Japanese sentence is often accompanied by a modal expression or a conjunctive particle such as kedo (though) and shi (also), especially in conversation. Japanese modality is structurally layered. Several modal expressions can be conjugated in a predicate. Figure 1 shows a Japanese clause structure suggested by Masuoka[32]. He views everything outside the proposition as modality, including tense and focus for example.
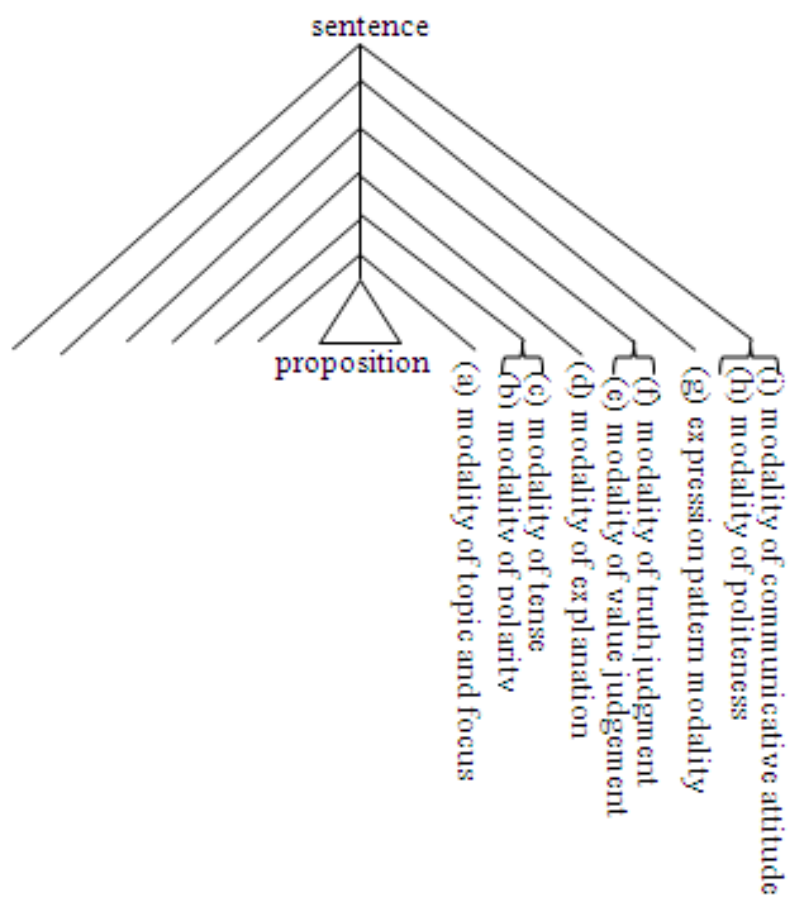

Figure 1. Layering of the Japanese clause structure, Masuoka (1991: 44)

1 Some researcher prefer to use the term 'agent-oriented modality'. See Bybee \& Fleischman[7] for details.
Among several types of modality, this paper focuses on modal expressions in a predicate position. We examine types (d), (e), (f), (g), and (i) in Masuoka's framework. Types (d) to $(\mathrm{g})$ are typically expressed by a bound morpheme attached to a verb, adjective, or noun inflection. Type (i) occupies the very final position in a predicate, and it is mainly used during interactive discourse. We use the term 'sentence final particles' (hereafter SFP) to refer to this modality (see example 1).

\begin{tabular}{|c|c|c|c|c|c|}
\hline \multirow[t]{2}{*}{ Taro } & wa & iku- & beki- & daroo & ne. \\
\hline & TOP & go & should & I:guess & \\
\hline
\end{tabular}

Some examples of modal forms and SFP are listed in Table 1. If a modal form has several meanings, one of the typical ones is indicated in parenthesis.

Table 1. Examples of Japanese modal forms and SFP

\begin{tabular}{|l|l|}
\hline Type of modality & \multicolumn{1}{|c|}{ Examples of modal forms and SFP } \\
\hline $\begin{array}{l}\text { (d) modality of } \\
\text { explanation }\end{array}$ & $\begin{array}{l}\text { noda (explanation), wakeda (consequence } \\
\text { description), kotoda (advice/order), monoda } \\
\text { (advice/general tendency) }\end{array}$ \\
\hline $\begin{array}{l}\text { (e) modality of } \\
\text { value judgment }\end{array}$ & $\begin{array}{l}\text { bekida (advice of social norm), nakuchaikenai } \\
\text { (obligation), temo-ii (permission) }\end{array}$ \\
\hline $\begin{array}{l}\text { (f) modality of } \\
\text { truth judgment }\end{array}$ & $\begin{array}{l}\text { kamoshirenai (subjective possibility), } \\
\text { (confirmation/speculation), sooda (prediction } \\
\text { from appearance), mitaida (conjuncture from } \\
\text { appearance) }\end{array}$ \\
\hline $\begin{array}{l}\text { (g) expression } \\
\text { pattern modality }\end{array}$ & tai (desire), $u$ (volition), tsumorida (intention) \\
\hline $\begin{array}{l}\text { (i) modality of } \\
\text { communicative } \\
\text { attitude (SFP) }\end{array}$ & yo, ne, no, yone, na, zo \\
\hline
\end{tabular}

Type (d), the modality of explanation, is used when a speaker or a writer gives an explanation or background information about the proposition. Type (e) and (g) express deontic meanings. Type (f) has epistemic meanings. In Type (i), the typical SFP are yo, ne, and no. The meaning of yo and ne incorporates the speaker's assumption about the status of the hearer's knowledge. The speaker uses yo to provide information that the hearer does not know. Ne is used when the speaker assumes that the hearer shares the information with the speaker. No has several functions, one of which is to indicate background information. Another function of no is as a question marker with a rising intonation or with a question word. Some researchers such as Koganemaru[22] and Tanomura[53] basically consider $n o$ as a variant of modal form noda. Many no and noda are difficult to distinguish. Noda[39] states that no and noda are compatible when indicating background information in a declarative sentence. However, no cannot be used in monologue and when expressing the speaker's judgement at the time of utterance. 
Both in speaking and in writing, speakers/writers consider the hearer/reader's state of mind and utilize a variety of modal expressions. This modality diversity and the speaker's constant evaluation of the hearer's mind brings about difficulties in acquiring modal expressions for non-native Japanese speakers.

\section{Previous Studies}

According to classic accounts, modality is divided into two types: epistemic modality and deontic modality. Sweetser[52] claims that deontic modality is prototypical. Aksu-Koç[1], Stephany[50][51], Wells[56] have suggested the predominance of deontic modality over epistemic modality in acquisition. Based on Brown[4], Choi[9], Kuczai[25], Shatz and Wilcoz[47], English modality begins emerging between $1 ; 10$ and 2;6. Stephany[50] explicates that children start using modal forms to express deontic meanings such as obligation, necessity, or permission first, and then after a year or so they start using modal forms to express epistemic meanings between $3 ; 0$ and 5;0. Matsui[33] summarized previous research that children are likely to produce certainty markers before they start using uncertainty markers. Children produce the marker of direct evidence before they use the marker of indirect evidence.

As for Japanese modality, acquisition of sentence final particles (SFP) is observed by many researchers. Clancy[10], Furuta, Shirai, Ono and Shirai[12], Iwadate and Ogura[21], Nagano[38], Nukada[40], Okubo[41], and other scholars have found that Japanese children start using SFP first. There are a variety of SFP in Japanese. A general consensus is that $y o$ and $n e$ emerge earlier in children's language development. The onset of yo and ne varies depending on the researcher, but it can be contained between $1 ; 5$ to $2 ; 4$, by summing up previous research. After producing yo and $n e$, children start using other SFP and some modal forms. Shirai, Shirai, and Furuta [49] investigated four children up to the age of 3, and surmised that the acquisition of yo seems to be affected by frequency of input from the child's caregivers. This is not the case with the other two SFP (kana and tte).
Research on the acquisition of modal forms by Japanese L1 children is limited, but we shall introduce some. Matsui, Yamamoto, and McCagg[34] conducted an experiment on a total of 97 children aging from 3 to 6 to investigate children's understanding of certainty markers (yo vs. kana, shitteru vs. omou) and evidential markers (yo vs. tte, mita vs. kiita). They found that 3-year-olds already had a fairly good understanding of the particles of speaker certainty yo and kana, but that their understanding of equivalent verbs (shitteru 'I know', omou 'I think', mita 'I saw', kiita 'I heard') remained poor. One possible reason for the earlier understanding of certainty particles is input frequency.

Maeda, Tamai, and Hamabe[30] observed a female child between $1 ; 9$ and 2;9 and later at the age of 3;2, and analyzed her predicate inflection forms. In their study, they briefly touched on the onset of modality. Here, we extract the modal forms and onset age from their study and line them up below ${ }^{2}$.

Another source of research is Sasaki and Kawaguchi[46]. They studied modal forms in compositions used by 520 Japanese native speakers at the primary, middle, high school, and college level, and also by Japanese language learners. They state that the younger children (1st to $3 \mathrm{rd}$ grade of primary school) hardly used modal forms, and about $70 \%$ of their sentences ended with a bare proposition. It takes until college before a student can utilize a variety of modal forms. Sasaki and Kawaguchi illustrate the following acquisition order of modality with inference meaning.

In most longitudinal studies, modality expressions were observed as a part of the discussion on inflection form acquisition, and the number of subjects is one or so. The study by Sasaki and Kawaguchi analyzed 520 subjects, but the data was writing samples. Maeda, Tamai, and Hamabe examined 97 children, but their research is a cross-sectional study using an experiment. Still llittle is known about the general acquisition order of modality in children. As a starting point for our discussion, we will investigate first if there is any developmental order. We examine monolingual children's natural speech in the next section.

\begin{tabular}{|c|c|c|c|c|c|c|c|}
\hline $\begin{array}{l}\text { mitaida } \\
\text { (seem) }\end{array}$ & $>\begin{array}{l}\text { sooda } \\
\text { (look like) }\end{array}$ & $>\begin{array}{l}\text { tai } \\
\text { (want) }\end{array}$ & $>\begin{array}{l}\text { te-ii } \\
\text { (may) }\end{array}$ & $>$ & $\begin{array}{l}u \text { (volition), deshoo (isn't?), wakeda (it's the } \\
\text { reason ...), nakute-ii (doesn't need to), ba-ii-n-da } \\
(\text { good if ...) }\end{array}$ & $>$ & $\begin{array}{l}\text { no-daroo (it would } \\
\text { be), no-desu (it would } \\
\text { be) }\end{array}$ \\
\hline $2 ; 2$ & $2 ; 3$ & $2 ; 6$ & $2 ; 7$ & & $2 ; 8$ & & $2 ; 9$ \\
\hline
\end{tabular}

Figure 2. Emergence order of modal expressions in Maeda, Tamai, and Hamabe

$\begin{aligned} & \begin{array}{l}\text { to omou } \\ (\text { I think) }\end{array}\end{aligned}>\begin{aligned} & \text { daroo } \\ & \text { (I guess) }\end{aligned}>\begin{aligned} & k a \\ & \text { (question marker) }\end{aligned}>\begin{aligned} & \text { hazuda } \text { (should be), yooda (it seems), rashii (it } \\ & \text { seems), sooda (likely) }\end{aligned}>\begin{aligned} & \text { kamoshirenai } \\ & \text { ni-chigainai (must be) }\end{aligned}$ be),

Figure 3. Order of modal forms expressing inference in Sasaki and Kawaguchi 


\section{Discussion}

\subsection{Acquisition of Modality by Monolingual Speakers}

We examine longitudinally collected data from five monolingual children. The data are obtained from the open corpus CHILDES. The ages of the subjects are as follows: Nanami (NN) is $1 ; 1-5 ; 0$, Hamasaki (HM) is 2:2-3;7, Tomito (TM) is $2 ; 11-5 ; 1$, Asato (AS) is $3 ; 0-5 ; 0$, and Arika (AR) is $3 ; 0-5 ; 1$. NN is a female, and the others are male.

In this paper, the onset of SFP has begun when the child has produced an SFP more than twice. The onset of the modal form is when the child has clearly uttered it. We did not count the modal expressions if the child's production is an exact repetition of the immediately preceding utterance by the caregiver. In general, a female child starts speaking earlier than a male child, and it applies in the case of subjects $\mathrm{NN}(\mathrm{f})$ and HM (m). The onset of NN's modality production was at $1 ; 8$. HM was a little late as he started using modality at 2;9. The first modality detected in the data is the SFP yo, followed by the SFP $n e$, for both NN and HM. An example of yo used in NN's utterance is omoi yo (It is heavy), and in HM's utterance it is chairoi aisu da yo (This is brown ice cream). Their examples are below ${ }^{3}$.

(2) $<$ NN bumped into something. Her mother rubbed her leg to ease her pain. Then, $\mathrm{NN}$ walked to something and tried to hold it>

$$
\begin{aligned}
& \text { MOM: tondet-ta? tondet-ta? itai no tondet-ta? } \\
& \text { fly-PAST fly-PAST pain thing fly-PAST } \\
& \text { 'Did (your pain) fly away? Did (it) fly away? Did the pain } \\
& \text { fly away?' } \\
& \mathrm{NN}: \quad \ldots \quad \text { baa }=\text {. } \\
& \text { MOM: ... doko iku no? doko iku no? } \\
& \text { where go } \mathrm{Q} \text { where go Q } \\
& \text { 'Where (are you) going? Where (are you) going?' } \\
& \rightarrow \text { NN: } \begin{array}{cc}
\text { omoi } & \text { yo. } \\
\text { heavy } & \text { SFP } \\
\text { 'It's heavy'. } &
\end{array}
\end{aligned}
$$

(3) $<\mathrm{HM}$ is eating ice cream. $>$

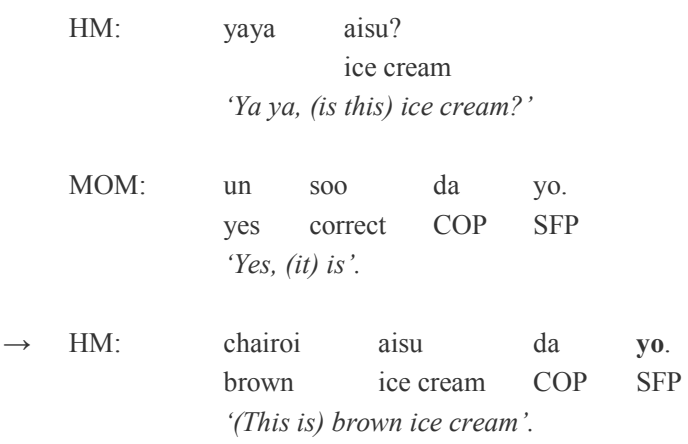

\footnotetext{
${ }^{3}$ In the examples, 'PAST' means a past morpheme. 'Q' indicates a question word. 'COP' refers a copula.
}

Once the child has produced a SFP, it was generally the case that the child continued to use it frequently in subsequent data. The data from Subjects TM, AR, and AS starts at $2 ; 11,3 ; 0,3 ; 0$ respectively. Their data contained some modal expressions from the beginning. This fact suggests that most children start using modal expressions before 3 years old.

The general tendency of modality development from the five monolingual children can be summarized as follows. Soon after children start producing the SFP yo and ne, they start using the verb te-form which expresses a request, and several other SFP (ex. yone, na, zo), $k a$ (question marker), no and noda (explanation) ${ }^{4}$. This is the time when they start producing sentences: Subject-Predicate structure. Thereafter, modal forms $u$ (volition) and daroo (confirmation/speculation) are exploited. The modal form daroo has several functions. The function that children used was confirmation as in tanoshii desho (It's fun, isn't?) and speculation as in doko daroo (I wonder where). After then, tai (desire) and nakuchaikenai (obligation) appear. Most children acquire potential forms, compound sentences, and polite forms at about 3;0. Around this time, children start using to omou (I think) between 3;0 and 3;9. There are individual differences, and kamoshirenai (subjective possibility) is added to the modal system before or after to omou. Hazuda (inevitability/estimation), wakeda (consequence description), rashii (presumption/hearsay), and monoda (advice/general tendency) emerge later between 3;11 and 4;9. The onset of temo-ii (permission), sooda (prediction from appearance/situation), and mitaida (conjuncture from appearance) varies by child.

Table 2 shows a diagram of the general modality development order from the five Japanese monolingual children. In this table, ' $\mathrm{S}$ ' means stage. We divide the emergence period of modal expressions into six stages. Modal expressions in the same stage do not necessary appear at the same time. Some could arrive earlier, and some could occur later during each stage depending on the child. This table shows the relative order of modal expressions that appear earlier than other forms occurring in the next stage. Grouping and ordering decisions are made when more than three children match.

\footnotetext{
${ }^{4} \mathrm{No}$ is also used as a substitution (akai no 'red one') and a possessive pronoun (watashi no 'mine). This type of no is not included in this paper, although children start using them early.
} 
Table 2. Emergence of modality in five monolingual children's language

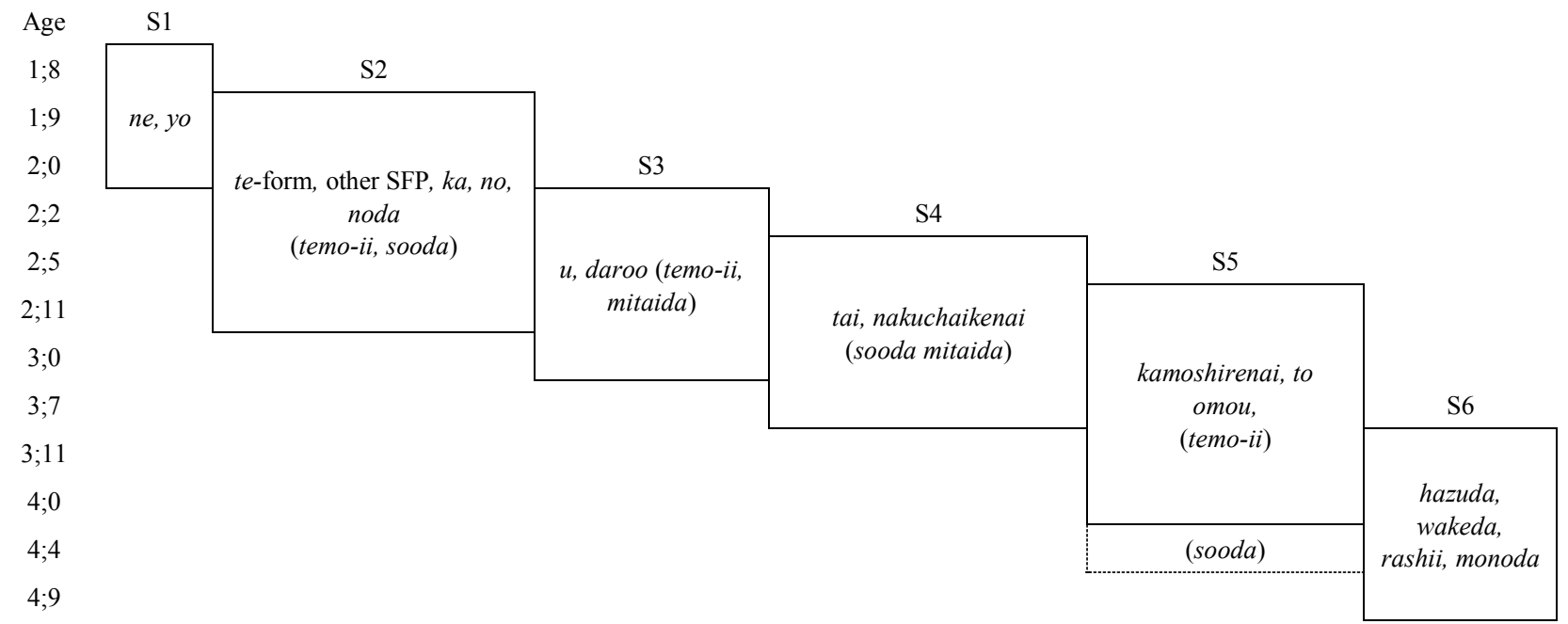

Our data shows that the acquisition order in writing suggested by Sasaki and Kawaguchi[46] does not exactly correspond to spontaneous speech data. In our data, $k a$ (question marker) and daroo (confirmation) appear much earlier than to omou (I think). In Saksaki and Kawaguchi's claim, to omou precedes to ka and daroo. To omou takes a subordinate clause, and children should have advanced linguistic ability to create such a structure. So our result would be more reasonable than Sasaki and Kawaguchi's order. Also, hazuda (inevitability/estimation) and rashii (presumption/hearsay) are produced later than kamoshirenai (subjective possibility) in our data. These orders are the opposite of Sasaki and Kawaguchi's assumption.

When compared with the result from Maeda, Tamai, and Hamabe[30], the modality acquisition of their subject is compatible with Table 2, except for tai (desire). Children in our study start using $u$ (volition) and daroo (confirmation) earlier than tai (desire).

Deontic modality deals with the necessity or possibility of acts performed by morally responsible agents, and it is thus associated with obligation, permission, and ability. Obligation and permission are expressed by nakuchaikenai and temo-ii (or te-ii) respectively, and ability is indicated by potential verb from (not by modal form) in Japanese. Nauchaikenai did not appear until Stage 4. Not all children started using temo-ii earlier; some did not produce it until Stage 5. This result suggests that deontic modality is not dominant at the beginning of the modality development in Japanese. Choi[8] claims that languages such as Korean, Japanese, and Turkish, which mark modality in bound morphemes, have shown early acquisition of evidential markers by children. Our finding may support her claim.

Another point worth mentioning from the data is the age of modality acquisition. Japanese SFP is not an obligatory category in that not all sentences must end with them. Similar to Yokoyama's[58] claim, children in our data also used a variety of SFP without making any mistakes from a very young age. The correct and early development of SFP indicates that children are capable of assessing the hearer's mind and they aspire to be good participants in conversation from early on. Sasaki and Kawaguchi[46] state that acquisition of modal forms progresses slowly and throughout school education. It is true that some modal forms with epistemic meaning such as bekida (advice of social norm) and ni-chigainai (validity) are not acquired at first in the children's language due to the limitations of their cognitive constraints. These modal forms are not found in the present data. However, our data shows that native Japanese children use a variety of and most major forms of modality felicitously and utilize them in interactional discourse at early stages of language development.

\subsection{Usage-based Model}

Most children start using a variety of SFP such as ne, yo, and no and several modal forms before the age of 3 . The question is whether they use them as underanalyzed strings without understanding their internal constituents or their functions. In other words, do children use SFP and modal forms as a chunk (a fixed expression), or just because a sentence "sounds better" with them?

There are two approaches in discussing language acquisition. One is the 'Dual Mechanism Model', and another is the 'Usage-based Model'. The Dual Mechanism Model, supported by Pinker[43] and Pinker \& Prince[44] assumes the vast expressive power of language is made possible by two principles: the arbitrary sound-meaning pairing underlying words, and the discrete combinatorial system underlying grammar. This theory explains that English regular past tense verbs are generated by rules and the irregular past tense verbs are stored in the lexicon. In this theory, a chunk is different from an application of rules, and it does not become productive linguistic ability to generate an infinite number of potential sentences.

Another approach is the Usage-based Models of language. It is based on cognitive grammar suggested by Langacker[27,28,29] and Bybee[5,6,7]. The usage-based 
theory of language acquisition makes the fundamental claim that language structure emerges from language use. Tomasello[55] claim that children understand communicative intentions, and they create abstract linguistic schemas or constructions through 'intention-reading' and 'pattern-finding' as they learn.

Major[31], Labov and Labov[26], Rowland and Pine[45], Dąbrowska[11] advocate that English native children first learn formulaic frames like 'Where's ? ?' and 'What's doing?' to make interrogative sentences, rather than starting by acquiring abstract rules such as subject-auxiliary inversion and WH movement. Tomasello[54] calls such formulaic frame 'pivot' schema, and he presents it as one of the utterance-level construction underlying children's earliest multi-word utterances. Pivot schema is originally proposed by Braine[3]. It is a multiword production which has a systematic pattern, like in examples 'see boy, see sock, see hot'. Braine found that the utterances produced by young children contain a few frequently occurring words which belong to a class of pivots $(\mathrm{P})$, and a complementary class which has many members that follow or precede the pivots, as XP or PX. Pivot schema is based on a claim that there is a structure that people prefer to use, and therefore it has an influence of input frequency.

The pivot schema is used by many acquisition researchers of Japanese as a second language. Sirahata[48] examined the acquisition of particle no. Hashimoto[15] claims that Japanese L2 children use schema ' $w a_{-},{ }^{\prime}$ '_ no _, ' analyzed verb inflections, negative forms, particles, and potential forms by using the schema. Iwadate[20,21] states that Japanese L1 children also learn individual expressions first, and they find a common schema from individual expressions such as the passive structure or the past form. And then they create abstract schema.

Now the question is wheather Japanese native children use SFP and modal forms as a chunk or in a schema.

Tomasello[55] states that pivot schema begins at around 18 months of age, and it emerges after word combinations (combination of two word or holophrases). Braine[3] claims that the consistent ordering patterns in many pivot schemas are very likely direct reproductions of the ordering patterns children have heard most often in adult speech, with no communicative significance. This means that although young children are using their early pivot schemas to partition scenes conceptually with different words, they are not using syntactic symbols - such as word order or case marking - to indicate the different roles being played by different participants in that scene.

At the time when children in our data started using modal forms, they were not in the two words stage anymore, but they were creating a Subject-Predicate structure. Otomo[42] measures the productivity by the type of context in which a certain form is used. For example, the productivity of the past tense morpheme $-t a$ is high if $-t a$ is used not only in tabe-ta (ate), but also in mi-ta (saw), or if it is used not only in an affirmative form but also in a negative form. In our data, children used modal forms in many affirmative sentences, however they used a variety of SFP and modal forms in different types of predicates: noun, adjective, and verb predicates. In this sense their productivity was not low. If we follow the usage-based theory, children must have understood the function of each SFP and modal forms, instead of using them without knowing their internal constitutions and functions. In fact, children used a variety of SFP and modal forms in a variety of structures. They did not use SFP and modal forms with any random proposition. If they are using modality in a pivot schema, we may find mistakes, like an example of particle errors produced by Japanese as L2 children in Hashimoto[14]. A subject in her data rely on the schema 'X no $\mathrm{Y}$ ' and produced 'boku no yaritai (I want to do it)'. But children in our data did not use a specific modality in a pivot schema and produced errors. They were using a variety of modal expressions correctly. Therefore, we predict that children understand the underlying structure and functions of basic SFP and modal forms when they use them.

\subsection{Acquisition of Modality by Bilingual Children}

\subsubsection{Developmental Progression of Modality}

Next we observe the acquisition of modality in a Japanese-English bilingual's language. We define the term bilingual as those who use two languages in everyday life. We examine the data obtained from a longitudinal study on three subjects: YU, KAR, KI. Their spontaneous conversations with their caregivers were recorded once a month during the following ages: YU is $2 ; 5-4 ; 0$, KAR is $5 ; 12-7 ; 2$, and KI is $9 ; 4-10 ; 0$. KAR is a female and the other two are male. Their parents are all Japanese native speakers. All subjects were born in Japan, and they had been living in the United States since YU was 2;3, KAR was 5;9, and KI was $8 ; 1$. YU and KAR were using English at school, but they were mostly speaking in Japanese with their parents at home, unless their parents initiated the conversation in English. KI, on the other hand, has lived in the US for one year and three months already at the time of his first data recording. KI was using English often at home.

In the first data, YU produced some SFP (yo, ne, yone, no, $k a$ ) and modal forms (daroo, u, noda, tai). Data on YU was collected up until 4;0, and Stage 6 modal forms (hazuda, wakeda, rashii, monoda) were not detected in his data. He generally followed the modality development order suggested from monolingual children's data in Table 2. KAR was 5;12 during her first data collection and she produced some SFP and modal forms (daroo, noda, tai, nakuchaikenai, kamoshirenai). During the next month, she produced to omou and wakeda. So, KAR's modality acquisition had reached Stage 6 from the very beginning. The oldest subject, KI, produced several SFP and only one modal form (noda) during his first data collection. He used only two modal forms (rashii, nakuchaikenai) in the last data collection. There is a possibility that low frequency of modal forms used by KI has a relation to bilingual acquisition. In the next 
section, we shall observe the frequency of modality in bilingual children's language.

\subsubsection{Frequency of Modality}

Table 3 shows the predicate types used in each subject's first and last data ${ }^{5}$. The upper row indicates the number of utterances, and the lower row shows the percentage. The total in the table is the total number and percentage of predicates with a modal form, SFP, a conjunctive particle, and their combination. The data excludes greetings, compellations like calling mother, fillers such as $e=$ and $u=n$, and short answers such as 'yes' and 'no'. A bare proposition refers to a sentence ending without a SFP or a modal form. A sentence ending with 'NP + particle' is categorized as a bare proposition. A sentence ending with -tte (quotation or insistence) or -kke (recall) is included in the SFP. A sentence ending with the verb conjugative te-form is included in a conjunctive particle. The imperative te-form from all subjects is not included in the table, because KI was explaining how to do magic in his last data, and used this form more frequently than usual.

Comparing the first and last data, the total percentage of predicates with a modal form, SFP, conjunctive particle, and its combination do not change much for both YU and KAR. However, the percentage in KI's last data has notably decreased (from $29.4 \%$ to $19.6 \%$ ). This may suggest a possibility that the bilingual development affects modality usage in Japanese. In order to investigate this postulation further, we compare speech from KI and a monolingual subject SM. SM was 6;10 in his last data and his age is the closest to KI among all subjects in the corpus CHILD ${ }^{6}$. Table 4 shows predicate forms in KI's first data at 9;4, his last data at $10 ; 0$, and SM's last data at $6 ; 10$.

Table 3. Predicate types used by bilinguals

\begin{tabular}{|c|c|c|c|c|c|c|c|c|c|c|}
\hline \multirow[b]{2}{*}{ subject } & \multicolumn{10}{|c|}{ Predicate Type } \\
\hline & $\begin{array}{c}\text { bare } \\
\text { proposition }\end{array}$ & $+\mathrm{MOD}$ & $+\mathrm{SFP}$ & + ConP & $\begin{array}{l}+ \text { MOD } \\
+ \text { SFP }\end{array}$ & $\begin{array}{l}+ \text { MOD } \\
+ \text { ConP } \\
\end{array}$ & $\begin{array}{l}+ \text { ConP } \\
+ \text { SFP } \\
\end{array}$ & total & truncated & $\begin{array}{c}\text { indeciphe } \\
\text { rable }\end{array}$ \\
\hline \multirow{2}{*}{$\begin{array}{c}\text { YU -1 } \\
(2 ; 5)\end{array}$} & 45 & 2 & 13 & 1 & 10 & - & - & 26 & 3 & 5 \\
\hline & $57.0 \%$ & $2.5 \%$ & $16.5 \%$ & $1.3 \%$ & $12.7 \%$ & & & $32.9 \%$ & $3.8 \%$ & $6.3 \%$ \\
\hline \multirow{2}{*}{$\begin{array}{l}\text { YU-2 } \\
(4 ; 0)\end{array}$} & 79 & 4 & 31 & 11 & 6 & 1 & 2 & 55 & 11 & 8 \\
\hline & $51.6 \%$ & $2.6 \%$ & $20.3 \%$ & $7.2 \%$ & $3.9 \%$ & $0.7 \%$ & $1.3 \%$ & $35.9 \%$ & $7.2 \%$ & $5.2 \%$ \\
\hline \multirow{2}{*}{$\begin{array}{c}\text { KAR-1 } \\
(5 ; 12)\end{array}$} & 49 & 4 & 11 & 11 & 3 & 1 & - & 30 & 9 & 13 \\
\hline & $48.5 \%$ & $4.0 \%$ & $10.9 \%$ & $10.9 \%$ & $3.0 \%$ & $1.0 \%$ & & $29.7 \%$ & $8.9 \%$ & $12.9 \%$ \\
\hline \multirow{2}{*}{$\begin{array}{c}\text { KAR-2 } \\
(7 ; 2)\end{array}$} & 65 & 4 & 18 & 5 & 3 & 1 & - & 31 & 2 & 6 \\
\hline & $62.5 \%$ & $3.8 \%$ & $17.3 \%$ & $4.8 \%$ & $2.9 \%$ & $1.0 \%$ & & $29.8 \%$ & $1.9 \%$ & $5.8 \%$ \\
\hline \multirow{2}{*}{$\begin{array}{l}\text { KI-1 } \\
(9 ; 4)\end{array}$} & 5 & 0 & 4 & 0 & 1 & - & - & 5 & 5 & 2 \\
\hline & $29.4 \%$ & $0.0 \%$ & $23.5 \%$ & $0.0 \%$ & $5.9 \%$ & & & $29.4 \%$ & $29.4 \%$ & $11.8 \%$ \\
\hline \multirow{2}{*}{$\begin{array}{c}\mathrm{KI}-2 \\
(10 ; 0)\end{array}$} & 34 & 1 & 8 & - & 1 & - & - & 10 & 5 & 2 \\
\hline & $66.7 \%$ & $2.0 \%$ & $15.7 \%$ & & $2.0 \%$ & & & $19.6 \%$ & $9.8 \%$ & $3.9 \%$ \\
\hline
\end{tabular}

Table 4. Comparison of predicate forms between bilingual and monolingual children

\begin{tabular}{|c|c|c|c|c|c|c|c|c|c|c|}
\hline \multirow[b]{2}{*}{ subject } & \multicolumn{10}{|c|}{ Predicate Type } \\
\hline & $\begin{array}{c}\text { bare } \\
\text { proposition }\end{array}$ & $+\mathrm{MOD}$ & $+\mathrm{SFP}$ & $+\mathrm{ConP}$ & $\begin{array}{l}+ \text { MOD } \\
+ \text { SFP }\end{array}$ & $\begin{array}{l}+ \text { MOD } \\
+ \text { ConP }\end{array}$ & $\begin{array}{l}+ \text { ConP } \\
+ \text { SFP }\end{array}$ & total & truncated & indecipherable \\
\hline \multirow{2}{*}{$\begin{array}{l}\text { KI-1 } \\
(9 ; 4)\end{array}$} & 5 & 0 & 4 & \multirow[t]{2}{*}{ - } & 1 & \multirow[t]{2}{*}{ - } & \multirow[t]{2}{*}{-} & 5 & 5 & 2 \\
\hline & $29.4 \%$ & $0.0 \%$ & $23.5 \%$ & & $5.9 \%$ & & & $29.4 \%$ & $29.4 \%$ & $11.8 \%$ \\
\hline \multirow{2}{*}{$\begin{array}{c}\mathrm{KI}-2 \\
(10 ; 0)\end{array}$} & 34 & 1 & 8 & \multirow[t]{2}{*}{-} & 1 & \multirow[t]{2}{*}{ - } & \multirow[t]{2}{*}{ - } & 10 & 5 & 2 \\
\hline & $66.7 \%$ & $2.0 \%$ & $15.7 \%$ & & $2.0 \%$ & & & $19.6 \%$ & $9.8 \%$ & $3.9 \%$ \\
\hline \multirow{2}{*}{$\begin{array}{c}\text { SM } \\
(6 ; 10)\end{array}$} & 18 & 2 & 12 & \multirow[t]{2}{*}{ - } & 6 & \multirow[t]{2}{*}{ - } & \multirow[t]{2}{*}{ - } & 20 & \multirow[t]{2}{*}{-} & \multirow[t]{2}{*}{ - } \\
\hline & $47.4 \%$ & $5.3 \%$ & $31.6 \%$ & & $15.8 \%$ & & & $52.6 \%$ & & \\
\hline
\end{tabular}

5 In the table, MOD stands for modal form, ConP stands for conjunctive particle.
6 SM's data is not included in Section 4.1: the discussion of monolingual children's modality acquisition, because SM uses dialect and his SFP forms are slightly different from other children. 
$\mathrm{KI}$ and SM's predicate type is either a bare proposition or with a modal expression (modal form, SFP, or their combination). KI should be expected to utilize a much wider variety of modal expressions than SM due to his advanced age. Nevertheless, the data depicts that the frequency of predicates with modal expressions in KI's first and last data are both much lower than the ones of SM. This result suggests that bilingual development could affect modality usage in Japanese.

\section{Conclusion}

This paper examined the Japanese modality used by monolingual children and Japanese-English bilingual children. The data in the present study shows that children produce a variety of SFP and modal forms at the early stages of language development.
Children start using SFP first. SFP has a rich discourse-interactional function, because they reflect the speaker's mind and his/her assumptions about the hearer's mind. Both monolingual and bilingual children acquire and produce SFP felicitously early on. Bilingual children who frequently use Japanese at home did not show a critical decline in the use of SPF, modal forms, conjugation particles, and their combinations. However, English dominant bilingual child tended to end a sentence without a modal expressions. The production rate is much fewer when compared to other bilingual children and also to a monolingual child.

Bedore and Peña[2] claim that it is difficult to evaluate whether the language development of bilingual children is normal or not. Our data suggests that the production frequency and adequate usage of modal forms could be used as an indicator in assessing the bilingual children's language development.

\section{APPENDIX: Meanings of modal expressions}

\begin{tabular}{|c|c|}
\hline$b a-i i-n d a$ & combination of $b a$ (condition form), ii 'good', and noda: 'it should be good if ...' \\
\hline bekida & advice of social norm: 'ought to' \\
\hline daroo (deshoo) & $\begin{array}{l}\text { confirmation/speculation: 'isn't it?', 'I guess' } \\
\text { * deshoo is a polite form of daroo }\end{array}$ \\
\hline hazuda & inevitability/estimation: 'should be' \\
\hline$k a$ & question marker \\
\hline kamoshirenai & subjective possibility: 'maybe' \\
\hline kotoda & advice/order \\
\hline mitaida & conjuncture from appearance: 'look like' \\
\hline monoda & advice/general tendency \\
\hline nakuchaikenai & obligation: 'must' \\
\hline ni-chigainai & validity: 'must be' \\
\hline noda & explanation \\
\hline no-daroo & combination of $n o(d a)$ and daroo \\
\hline no-desu & polite form of noda \\
\hline rashii & presumption/hearsay 'it seems' 'I heard' \\
\hline sooda & prediction from appearance/situation: 'it seems' \\
\hline tai & desire: 'want' \\
\hline te-ii & permission: 'may' \\
\hline temo-ii & permission: 'may' \\
\hline to omou & 'I think' \\
\hline yooda & prediction from appearance: 'it seems' \\
\hline wakeda & consequence description \\
\hline
\end{tabular}




\section{DATA: CHILDES}

1. N. Hamasaki. The Timing Shift of Two-Year-Olds' Responses to Caretakers' Yes/No Questions. In Y. Shirai, H. Kobayashi, S. Miyata, K. Nakamura, T. Ogura, and H. Sirai (Eds.), Studies in Language Sciences 2, 193-206, 2002.

2. N. Hamasaki. Japanese - Hamasaki Corpus Pittsburgh. PA: TalkBank. 1-59642-053-7, 2004.

3. B. MacWhinneyThe CHILDES project: Tools for analyzing talk. Third Edition. Mahwah, NJ: LEA, 2000.

4. S. Miyata and Y. H. Nisisawa. Japanese - MiiPro Asato Corpus. Pittsburgh, PA: TalkBank. ISBN 1-59642-474-5, 2009.

5. S. Miyata and Y. H. Nisisawa. Japanese - MiiPro Tomito Corpus. Pittsburgh, PA: TalkBank. ISBN 1-59642-472-9, 2010.

6. Y. H. Nisisawa and S. Miyata. Japanese -MiiPro Nanami Corpus. Pittsburgh, PA: TalkBank. ISBN 1-59642-473-7, 2009.

7. Y. H. Nisisawa and S. Miyata. Japanese - MiiPro ArikaM Corpus. Pittsburgh, PA: TalkBank. ISBN 1-59642-475-3, 2010.

8. J. Noji, N. Naka, and S. Miyata. Japanese Noji corpus. PA: TalkBank. 1-59642-058-8, 2004.

\section{REFERENCES}

[1] A. Aksu-Koç. The acquisition of aspect and modality: The case of past reference in Turkish, Cambridge University Press, UK, 1988.

[2] L. M. Bedore, E. D. Peña. Assessment of bilingual children for identification of language impairment: current findings and implications for practice, International Journal of Bilingual Education and Bilingualism, 11(1), 1-29, 2008.

[3] M. D. S. Braine. The ontogeny of English phrase structure: The first phase, Language, 39, 1-14, 1963.

[4] R. Brown. A first language: The early stages, Harvard University Press, USA, 1973.

[5] J. Bybee. Regular morphology and the lexicon, Language and Cognitive Processes, 10, 425-455, 1995.

[6] J. Bybee. Morphology, John Benjamins, Amsterdam, 1985.

[7] J. Bybee, S. Fleischman. Modality in grammar and discourse: An introductory essay, In J. Bybee and S. Fleischman (Eds.), Modality in grammar and discourse (pp.1-14), Benjamins, Netherlands, 1995.

[8] S. Choi. Acquisition of modality, In W. Frawley, E. Eschenroeder, S. Mills, and T. Nguen (Eds.), The expression of modality (pp. 141-171), Mouton de Gruyter, Germany, 2006.

[9] S. Choi. Early acquisition of epistemic meanings in Korean: A study of sentence - ending suffixes in the spontaneous speech of three children, First Language, 11, 93-119, 1991.

[10] P. Clancy. The acquisition of Japanese. In D. I. Slobin (Ed.), The Crosslinguistic study of language acquisition vol. 1: The data (pp.373-524), Lawrence Erlbaum, USA, 1985.

[11] E. Dąbrowska. From formula to schema: The acquisition of English questions, Cognitive Linguistics, 11, 83-102, 2000.

[12] Y. Furuta, J. Shirai, S. Ono, H. Shirai. San-sai made no yoji ni okeru bunmatsu hyogen no syutoku, Annual meeting of the Japanese Cognitive Science Society, 15, 272-273, 1998.

[13] Y. Hashimoto. Nihongo o dai-ni gengo tosuru Eigo/Futsugo bogo youji no hiteikei no shutoku purosesu - sukima seisei ni motozuku gengo kouzou no hattatsu -, Dai ni gengo toshite no Nihongo no syutoku kenkyu, 14, 60-79, 2011.

[14] Y. Hashimoto. Nihongo o dai ni gengo tosuru yoji no gengo-kozou no kochiku - joshi 'no' to 'ga' no sukima seisei ni chumoku shite-, Dai ni gengo toshite no Nihongo no syutoku kenkyu, 12, 46-65, 2009.

[15] Y. Hashimoto. Nihongo o dai ni gengo tosuru youji no sukima seisei ni yoru bun kouzou no kouchiku purosesu - shiyo izon moderu no kanten kara joshi no siyo ni shoten o atete-, Nihon ninchi gengo gakkai ronbunshu, 8, 328-337, 2008.

[16] Y. Hashimoto. Yoji no dai ni gengo no sukima seisei ni motozuku gengo kozo no hattatsu - Dai ichi gengo ni okeru kanokei shutoku to no hikaku -, Dai ni gengo toshite no Nihongo no syutoku kenkyu, 10, 28-47, 2007.

[17] Y. Hashimoto. Yoji no dai ni gengo to shite no doshikei no syutoku purosesu - sukima-seisei ni motozuku gengo kozo no hattatsu -, Dai ni gengo to shiteno Nihongo shutoku kenkyu, 9, 23-41, 2006.

[18] M. Inoue. Modaliti, In Takuichiro Onishi (Ed.), Hogen bunpo chosa gaido bukku (pp. 133-150), Kokuritsu kokugo kenkyusho zenkoku hogen chosa iinkai, Japan, 2002.

[19] S. Iwadate. Bumpo no kakutoku 1: doshi o chushin ni, In M. Sasaki \& H. Kobayashi (Eds.), Kodomotachi no gengo kakutoku, Taishukan, Japan, 1997.

[20] S. Iwadate. Bumpo no kakutoku: rokaru ruru kara gurobaru ruru e, Gengo, 21, 46-51, 1992.

[21] S. Iwadate, T. Ogura. (Eds.). Yokuwakaru gengo hattasu, Mineruva, Japan, 2005.

[22] H. Koganemaru. Mudo no 'noda' to sukopu no 'noda', Nihongogaku, 9(3), 72-82.

[23] Kokuritsu kokugo kenkyusho. (Ed.). Nihonjin no chishiki kaiso ni okeru hanashi-kotoba no jittai, Kokuritsu kokugo kenkyusho [National Institute for Japanese Language and Linguistics], Japan, 1980.

[24] Y. Kubo. Yoji no gengo no hattatsu, Jido kenkyusho kiyo, 5, 1922.

[25] S. Kuczai, M. Maratos. Initial verbs of yes-no questions: A different kind of general grammatical category, Developmental Psychology, 19, 440-444, 1983.

[26] W. Labov, T. Labov. Learning the syntax of questions, Recent Advances in the Psychology of Language, vol. 4B, Plenum Press, New York, 1-44, 1978.

[27] R. Langacker. Concept, image, and symbol: The cognitive basis of grammar, Mouton de Gruyler, NY, 1991

[28] R. Langacker. A usage-based model. In B. Rudzka-Ostyn (Ed.), Topics in cognitive linguistics, John Benjamins, Amsterdam, 1988. 
[29] R. Langacker. Foundations of cognitive grammar, vol. 1. Stanford University Press, 1987

[30] K. Maeda, Y. Tamai, M. Hamabe. On the language development of an infant, Bulletin of the Faculty of Humanities and Social Sciences, Ube Frontier University, 1(1), 25-36, 2010.

[31] D. Major. The acquisition of modal auxiliaries in the language of children. The Hague: Mouton, 1974

[32] T. Masuoka. Modaliti no bunpo, Kuroshio, Japan, 1991.

[33] T. Matsui. Children's understanding of linguistic expressions of certainty and evidentiality, In D. Matthews (Ed.), Pragmatic development in first language acquisition, John Benjamins, The Netherlands, Philadelphia, 2014.

[34] T. Matsui, T. Yamamoto, P. McCagg. On the role of language in children's early understanding of others as epistemic beings. Cognitive Development, 21, 158-173, 2006.

[35] K. S. Maynard. Kaiwa bunseki, Kuroshio, Japan, 1993.

[36] A. Mikami. Shintei gendai gohou-josetsu, Toukou-shoin, Japan, 1959.

[37] N. Mizutani. Aizuchi to outoo, In O. Mizutani (Ed.), Hanashiktoba no hyogen (pp.37-44), Chikuma shobo, Japan, 1983.

[38] M. Nagano. Yoji no gengo hattatsu - tokuni josho 'no' no shutoku katei ni tsuite -, Kansai daigaku kokubun gakkai Shimada kyoju koki kinen kokubungaku ronshu (pp.405-418), Kansai daigaku kokubun gakkai, 1960.

[39] H. Noda. 'Noda' to shujosho 'no' no kyokai o megutte, Nihongogaku, 12(11), 43-50, 1993.

[40] K. Nukada. Yoji no gengo hattatsu [The development of language of children], Kaseigaku zasshi, 28(2), 145-150, 1977.

[41] A. Okubo. Yoji-gengo no hattatsu, Tokyodo, Japan, 1967.

[42] K. Otomo. Comparative research for a developmental index for first and second language of Japanese and English, Grant-in-Aid for Scientific Research (B), 2004.

[43] S. Pinker. Words and rules, Lingua, 106, 219-242, 1998.

[44] S. Pinker, A. Prince. Regular and irregular morphology and the psychological status of rules of grammar, In S. Lima, R. Corrigan, \& G. Iverson (Eds.), The reality of linguistic rules (pp. 321-351), John Benjamins, Philadelphia, , 1994.

[45] C. Rowland, J. Pine. Subject-auxiliary inversion errors and wh-question acquisition: "What children do know?", Journal of Child Language, 27, 157-181, 2000.

[46] Y. Sasaki, R. Kawaguchi. Nihonjin shogakusei, chugakusei, koukousei, daigakusei to Nihongo gakushusha no sakubun ni okeru bunmatsu hyogen no hattatsu katei ni kansuru ichi kousatsu, Nihongo kyoiku, 84, 1-13, 1994.

[47] M. Shatz, S. Wilcox. Constraints on the acquisition of English modals, In S. Gelman and J. Byrnes (Eds.), Perspectives on language and thought: Interrelations in development (pp.319-353), Cambridge University Press, UK, 1973.

[48] T. Shirahata. Yoji no dai ni gengo toshite no Nihongo kakutoku to 'no' no kajo seisei - Kankokujin youji no judan kenkyu -, Nihongo kyoiku 81, 104-115, 1993.

[49] J. Shirai, H. Shirai, Y. Furuta. Acquisition of sentence-final particles in Japanese. In M. Parkins \& S. Howards (Eds.), New directions in language development and disorders (pp.243-250), Plenum Press, NY, 1999.

[50] U. Stephany. Function and form of modality in first and second language acquisition, In A. G. Ramat and G. C. Galeas (Eds.), From pragmatics to syntax: Modality in second language acquisition (pp.105-120), Gunter Narr Verlag, Germany, 1995.

[51] U. Stephany. Modality. In P. Fletcher and M. Garman (Eds.), Language acquisition (pp.375-400), Cambridge University Press, UK, 1986.

[52] E. Sweetser. From Etymology to pragmatics: Metaphorical and cultural aspects of semantic structure, Cambridge University Press, UK, 1990.

[53] T. Tanomura. Gendai Nihongo no bunpo I - 'noda' no imi to youhou. Izumi sensho, Japan. 1990.

[54] M. Tomasello. First steps toward a usage-based theory of language acquisition. Cognitive Linguistics, 11(1-2), 61-82, 2001.

[55] M. Tomasello. The usage-based theory of language acquisition, In Edith L. Bavin (Ed.), The Cambridge handbook of child language (pp.69-87), Cambridge University Press, Cambridge, 2009.

[56] G. Wells. Language development in the preschool years, Cambridge University Press, UK, 1985.

[57] Y. Yamada. Nihon bunpo gaku gairon, Hobunkan, Japan, 1936.

[58] M. Yokoyama. Yoji ni yoru joshi no goyo no shutsugen jiki to ruikei, Fukuoka kyoiku daigaku kiyo dai yon bun satsu Kyoshokuka hen - [Bulletin of Fukuoka University of Education], 38, 225-236, 1989. 